\title{
A JUDICIALIZAÇÃO DA POLÍTICA E O PROTAGONISMO DOS JUÍZES NAS DECISÕES QUE ENVOLVEM O DIREITO CONSTITUCIONAL À SAÚDE: REFLEXÕES ACERCA DA JURISDIÇÃO CONSTITUCIONAL
}

\author{
THE JUDICIALIZATION OF POLICY AND PROTAGONISM OF JUDGES IN \\ DECISIONS INVOLVING THE CONSTITUTIONAL RIGHT TO HEALTH: \\ REFLECTIONS ON THE CONSTITUTIONAL JURISDICTION
}

\section{RESUMO}

A despeito das fervorosas críticas da doutrina, direcionadas à Jurisdição constitucional e ao protagonismo dos juízes, sob o argumento que a atuação destes tem judicializado a política, o que vem se observando é um protagonismo cada vez maior do Poder Judiciário no Brasil. Em questões como a do direito constitucional à saúde, tal protagonismo apresenta-se de forma consorciada com uma grande esperança dos cidadãos no que se refere à efetivação desses direitos mais fundamentais e que historicamente foram relegados a um segundo plano pelos demais poderes constituídos. Entretanto, mesmo diante da euforia e da relevância dessa atuação comprometida com o aspecto social e humanitário, urge que não sejam esquecidas as bases do Constitucionalismo Democrático e que o princípio da proporcionalidade seja plenamente observado a cada decisão proferida.

Palavras-chave: Constituição; Direito à saúde; Judicialização da política; Protagonismo dos Juizes.

\begin{abstract}
Despite the fervent criticism of the doctrine, directed to jurisdiction constitutional and protagonism of judges, arguing that these actions have judicialized the policy, which has been observed is a protagonism growing for the judiciary in Brazil. On issues like the constitutional right to health, this role is presented as a great hope of the citizens with regard to the effectiveness of these most fundamental rights which have historically been relegated to the sidelines by the other powers that be. However, despite the euphoria and the relevance of this activity committed with the social and humanitarian aspect can not be forgotten the base of Democratic Constitutionalism and the principle of proportionality should is fully observed every judgment.
\end{abstract}

Keywords: Constitution; Right to health; Judicialization of politics; Protagonism of judges. 
A JUDICIALIZAÇÃO DA POLÍTICA E O PROTAGONISMO DOS JUIZZES NAS DECISÕES QUE ENVOLVEM O DIREITO CONSTITUCIONAL À SAÚDE: REFLEXÕES ACERCA DA JURISDIÇÃO CONSTITUCIONAL

\section{SUMÁRIO}

INTRODUÇAO; 1 A CONSTITUIÇÃO ENQUANTO FENÔMENO CULTURAL: UMA ANÁLISE DA CARTA POLÍTICA À LUZ DE PETER HÄBERLE; 2 O PROTAGONISMO DOS JUÍZES: MOTIVO E CONTEXTO HISTÓRICO; 3 A JUDICIALIZAÇÃO DA POLÍTICA: UMA ANÁLISE DOS REFLEXOS DO ATIVISMO DIGITAL NO DIREITO À SAUDE; CONCLUSÃO; REFERÊNCIAS.

\section{INTRODUÇÃO}

O presente artigo tem por objetivo analisar o papel que a jurisdição constitucional vem desempenhando hodiernamente. Para isso o texto possui três momentos distintos, destinados a realizar uma abordagem acerca da constituição enquanto fenômeno cultural à luz das obras de Peter Häberle, o contexto histórico e os motivos que conduziram ao crescente protagonismo dos juízes, bem como a judicialização da política, sobretudo no que tange ao ativismo nas ações que envolvem o direito à saúde.

Nessa perspectiva, inicialmente buscar-se-á trabalhar com uma análise da Carta Política enquanto um documento que reflete muito da vivência de seu povo, dos valores, tradições e, sobretudo, o momento histórico em que é elaborada.

Num segundo momento, realizar-se-á uma análise acerca do protagonismo dos juízes, causas e contexto histórico que conduziram para a proeminência do Poder Judiciário frente aos demais poderes.

Igualmente, em um terceiro momento, trabalhar-se-á com os aspectos da judicialização da política, sobretudo no que tange ao ativismo judicial nas questões que envolvem o direito à saúde.

Estruturar-se-á o texto, genericamente, a discorrer acerca da necessidade de efetivação dos direitos fundamentais, a partir da compreensão de que o ativismo judicial, embora não seja a medida adequada, na maioria dos casos acaba sendo o meio mais eficaz para que o cidadão alcance a concretização destes direitos. 


\section{A CONSTITUIÇÃO ENQUANTO FENÔMENO CULTURAL: UMA ANÁLISE DA CARTA POLÍTICA À LUZ DE PETER HÄBERLE}

A Constituição de um Estado traz insculpida em sua redação muito da vivência de seu povo, dos valores, tradições e, sobretudo, reflete o momento histórico em que é elaborada. Embora a Carta Política tenha a função de estabelecer o funcionamento e organização do Estado a sua característica preponderante consiste justamente na incorporação forte e robusta de elementos culturais, responsáveis por garantir a coerência e coesão do referido documento com as características do povo e do Estado a que se refere.

Neste contexto, adotar-se-á por marco teórico do presente tópico o pensamento de Häberle, a escolha se justifica na medida em que a judicialização da política tem sido fundamentada, sobretudo, na consolidação da força normativa da Constituição, bem como na compreensão de que tal texto normativoé um instrumento que reflete o sentimento de cultura e carrega dentro de si os valores da comunidade.

Assim, o termo Constituição não significa única e exclusivamente ordenamento jurídico para juristas, que terão a incumbência de interpretá-la seguindo as regras exegéticas. Ela serve também de norte para todo o cidadão. A Constituição não se limita somente a ser um conjunto de textos jurídicos ou um mero compêndio de regras normativas, ela é mais do que isso, a Constituição é a expressão de uma auto representação própria de todo um povo, espelho de seu legado cultural e fundamento de suas esperanças e desejos ${ }^{1}$.

Logo, a Constituição projeta o povo para que tenha esperanças e perspectivas de futuro. Assim, a Carta Política surge como um conjunto de regras vinculadas às influências do meio social e um guia para toda a sociedade.

Do mesmo modo, a interpretação constitucional é, em realidade, mais um elemento da sociedade aberta. Todas as potências públicas, participantes materiais do processo social, estão nela envolvidas, sendo ela, a um só tempo, elemento resultante da sociedade aberta e um

\footnotetext{
${ }^{1}$ HÄBERLE, Peter. Teoria de La Constitución como ciencia de la cultura. Traducción de Emilio Mikunda. Madrid: Tecnos, 2002, p. 34.
} 
A JUDICIALIZAÇÃO DA POLÍTICA E O PROTAGONISMO DOS JUÍZES NAS DECISÕES QUE ENVOLVEM O DIREITO CONSTITUCIONAL À SAÚDE: REFLEXÕES ACERCA DA JURISDIÇÃO CONSTITUCIONAL

elemento formador ou constituinte dessa sociedade, assim, os critérios de interpretação constitucional hão de ser tanto mais abertos quanto mais pluralista for a sociedade ${ }^{2}$.

Nesta senda, o conceito de interpretação reclama um esclarecimento: quem vive a norma acaba por interpretá-la, ou seja, toda atualização da Constituição, por meio da atuação de qualquer indivíduo, constitui, uma atividade que se dirige à compreensão e à explicitação de sentido de uma norma. Em outros termos, o destinatário da norma é participante ativo do processo hermenêutico ${ }^{3}$. Logo, a interpretação constitucional é uma atividade que, potencialmente, diz respeito a todos ${ }^{4}$.

A interpretação constitucional passa a ser, assim, um elemento fundamental de compreensão da própria essência da norma. Ademais, como numa sociedade pluralista admitemse critérios mais abertos, em virtude das características próprias dessa sociedade, vários são os elementos, a partir dos quais será manifestada a liberdade cultural e, consequentemente, a interpretação das normas constitucionais.

A liberdade cultural é liberdade plena, que se manifesta a partir de elementos como a religião, a arte e a ciência, sendo uma liberdade que vai além do estado natural rousseauniano ou, que vai além da própria humanidade interpretada como cultura. A liberdade artística coopera a configurar o status civilis como status culturalis, e a este, por sua vez como status mundialis ${ }^{5}$.

Neste contexto, tanto a proteção dos bens culturais como as liberdades que poderíamos denominar "especificamente culturais", como as disposições relativas a todo legado ou herança cultural, assim como todo o restante articulado, ínsito a qualquer ordenamento jurídico que haja sido estabelecido tomando a cultura por base, tudo isso considerado em seu conjunto, reflete em particular o que poderíamos denominar de "a dimensão cultural de toda a Constituição" 6 .

Destarte, se depreende que a Constituição é, sobretudo, expressão viva de um status quo cultural já alcançado que se encontra em permanente evolução, um meio pelo qual o povo possa

\footnotetext{
${ }^{2}$ HÄBERLE, Peter. Hermenêutica Constitucional: a sociedade aberta dos intérpretes da Constituição contribuição para a interpretação pluralista e procedimental da Constituição. Tradução de Gilmar Ferreira Mendes. Porto Alegre: Fabris, 1997, p. 13.

3 Ibid., p.14-15.

4 Ibid., p. 24.

${ }^{5}$ HÄBERLE, Peter. Teoria de la Constitución como ciencia de la cultura.Traducción de Emilio Mikunda. Madrid: Tecnos, 2002, p. 83.

6 Ibid., p. 145.
} 
A JUDICIALIZAÇÃO DA POLÍTICA E O PROTAGONISMO DOS JUÍZES NAS DECISÕES QUE ENVOLVEM O DIREITO CONSTITUCIONAL À SAÚDE: REFLEXÕES ACERCA DA JURISDIÇÃO CONSTITUCIONAL

encontrar-se a si mesmo através de sua própria cultura, ou seja, um espelho fiel de herança cultural e fundamento de toda esperança ${ }^{7}$.

Dentre os elementos de identidade cultura que integram o Estado Constitucional, destaca-se um elemento que não costuma ser observado: o direito ao feriado. Mais do que qualquer outro direito, o feriado tem uma vinculação direta com a cultura, pois são destinadas datas específicas, com o condão de que todas as pessoas daquele Estado reflitam e comemorem conquistas ou lutas marcantes para aquele contexto social.

O direito ao feriado faz parte de um grupo de normas constitucionais que são geralmente desconsideradas, mas que alcançam o centro de identidade cultural do Estado Constitucional. Elas derivam da “matéria” a partir da qual se tem também “sonhos”, mas são, sobretudo, os valores fundamentais que tocam o lado emocional da pessoa e do cidadão no Estado Constitucional: hinos, bandeiras, objetivos educacionais como "amor ao povo e à pátria", “reconciliação de povos", assim como monumentos ${ }^{8}$.

Somente o princípio da ciência da cultura consegue evidenciar possibilidades e limites dos feriados no Estado Constitucional, pois o positivismo jurídico estatal não consegue apresentar alternativas. Assim, todos os feriados festejados são "dias constitucionais", uma vez que procuram conscientizar diversos elementos do Estado Constitucional na formação de um todo. Ademais, a pessoa e o cidadão têm uma necessidade de festejar para entrar em consonância com o meio ambiente, sentir-se parte da comunidade?

Para fundamentar o argumento de que a Constituição é um espelho da identidade cultural do Estado que regula, na obra "Os problemas da verdade do Estado Contitucional”, o autor demonstra a tentativa de interpretar o Estado constitucional como um fórum da busca pelas verdades, amparando aqui, a partir desta análise, muitos dos argumentos já apresentados nas obras retro mencionadas.

Assim, Häberle entende que a tentativa de interpretar o Estado constitucional como fórum da busca pelas verdades é amparada por duas linhas de fundamentação: a primeira, da sua constituição subjetiva, se fundamenta a partir das três liberdades fundamentais: religião,

\footnotetext{
${ }^{7}$ HÄBERLE, Peter. Teoria de la Constitución como ciencia de la cultura.Traducción de Emilio Mikunda. Madrid: Tecnos, 2002, p. 145.

${ }^{8}$ HÄBERLE. Peter. Constituição e cultura: 0 direito ao feriado como elemento de identidade cultural do Estado Constitucional. Rio de Janeiro: Lumen Juris, 2008, p. 21-22.

9 Ibid., p. 23.
} 
A JUDICIALIZAÇÃO DA POLÍTICA E O PROTAGONISMO DOS JUÍZES NAS DECISÕES QUE ENVOLVEM O DIREITO CONSTITUCIONAL À SAÚDE: REFLEXÕES ACERCA DA JURISDIÇÃO CONSTITUCIONAL

arte e ciência; assim como, a segunda, de maneira preponderantemente objetiva, a partir de uma ordenação das cláusulas de pluralismo ${ }^{10}$.

Num questionamento exacerbado acerca da problemática da verdade deve-se inquirir se as ordens jurídicas, inclusive as constituições, podem “mentir”. Esse questionamento é legítimo, pois o direito positivo também é obra da imperfeição humana. Já por isso é necessário inquirir sobre as constituições positivas e reinquirir, pois a positividade sempre deve ser questionada ${ }^{11}$.

Diante da referida discussão, para Häberle, deveríamos tomar sensivelmente conhecimento da discussão filosófica da verdade, mas, como juristas, não deveríamos acolher simplesmente uma definição da verdade; ela poderia ser apenas um aspecto parcial que foi generalizado. Ademais já existem tentativas da própria filosofia de combinar a "teoria da correspondência" com a teoria da coerência. Desta forma, a teoria do consenso se deixa inserir na teoria da constituição sob a veste de um “consenso fundamental” que deve ser constantemente reformulado no sentido de um consenso ético mínimo ${ }^{12}$.

Ainda cumpre referir, que a imagem da pessoa humana no Estado constitucional prevê um cidadão, ao qual a busca da verdade é possível, bem como, necessita de verdades. Isso pressupõe tanto a não-violência (devido ao monopólio da força do Estado) quanto a tolerância, cultura, proteção à natureza e também as gerações futuras ${ }^{13}$.

Nesta mesma linha de raciocínio, no que se refere ao aspecto cultural se observa que de forma evidente o Direito na Europa reflete muito de sua cultura, notadamente em alguns aspectos em especial, confirmando a argumentação acima exposta de que a Constituição é, sobretudo, um fenômeno cultural.

A Europa vive, particularmente, uma forma específica de Direito e de sua cultura jurídica; o direito romano e a religião cristã são considerados seus mais antigos fundamentos. Através das lutas pela liberdade, justiça e bem comum, a Europa criou paradigmas que pertencem à herança cultural da humanidade como genes culturais. A cultura europeia se contrapõe às culturas de outras áreas geográficas, na medida em que muitos de seus elementos nasceram com vocação de universalidade - os direitos humanos desde 1789, a dignidade humana

\footnotetext{
${ }^{10}$ HÄBERLE, Peter. Os problemas da verdade no Estado Constitucional. Tradução de Urbano Carvelli. Porto Alegre: Fabris, 2008, p. 108.

11 Ibid., p. 121.

${ }^{12}$ HÄBERLE, Peter. Os problemas da verdade no Estado Constitucional. Tradução de Urbano Carvelli.

Porto Alegre: Fabris, 2008, p.126.

${ }^{13}$ Ibid., p. 128.
} 
A JUDICIALIZAÇÃO DA POLÍTICA E O PROTAGONISMO DOS JUÍZES NAS DECISÕES QUE ENVOLVEM O DIREITO CONSTITUCIONAL À SAÚDE: REFLEXÕES ACERCA DA JURISDIÇÃO CONSTITUCIONAL

como premissa antropológica, sentido e meta da ordem política, a doutrina da justiça, 0 princípio democrático, o Estado de Direito, a divisão de poderes e a economia de mercado ${ }^{14}$.

Um traço marcante do direito na Europa é a ideia que nasce na Revolução Francesa de universalizar valores. Desse modo, os elementos estruturais e as funções do Estado constitucional determinante desde 1789 já se tornaram clássicos e permanecem como tais: caráter escrito das constituições; liberdade, igualdade e fraternidade, ou direitos fundamentais do indivíduo como direitos inatos; declarações de direitos humanos em conjunto, assim como direitos singulares, em seu conteúdo, áreas e funções protetoras; ideia de codificação e positivação do Direito com a dialética, vontade geral e procedimento legislativo ${ }^{15}$.

Outrossim, o ano de 1789 foi, em termos de dogmática constitucional, uma garantia cultural com determinados conteúdos irrenunciáveis para o Estado constitucional. Os direitos do homem e seu fundamento, a dignidade humana, a separação de poderes, assim como a democracia, formam barreiras culturais que não permitem qualquer retrocesso, além de conceber elementos básicos de todo avanço constitucional para o futuro ${ }^{16}$.

Diante do exposto, observa-se a figura da Constituição enquanto resultado de um processo cultural, fundamentada em uma teoria da constituição enquanto uma ciência da cultura, que se encontra profundamente vinculada na sociedade e no cidadão.

A totalidade da obra de Peter Häberle conduz a figura de uma constituição dinâmica, cuja interpretação resulta da compreensão que todos os seus destinatários, que impede o modelo totalitário ao afirmar a harmonia e a independência existente entre os três poderes e enfatiza a necessidade de serem observados os direitos fundamentais, enquanto instrumentos promotores de uma cultura pautada nos valores da liberdade, igualdade e fraternidade.

\section{O PROTAGONISMO DOS JUÍZES: MOTIVOS E CONTEXTO HISTÓRICO}

A compreensão da necessidade de se ter uma Constituição que passe a regular as ações do Estado e a própria figura do Estado de Direito, fundamentada no direito natural à igualdade e na ideia do contrato social, nasce em uma sociedade que não quer mais conviver com o regime

\footnotetext{
${ }^{14}$ HÄBERLE, Peter. Libertad, igualdad, fraternidad: 1789 como historia, actualidad y futuro del Estado Constitucional. Madrid: MinimaTrotta, 1998, p. 11.

${ }^{15}$ Ibid., p. 76-77.

${ }^{16}$ Ibid., p. 87-88.
} 
A JUDICIALIZAÇÃO DA POLÍTICA E O PROTAGONISMO DOS JUÍZES NAS DECISÕES QUE ENVOLVEM O DIREITO CONSTITUCIONAL À SAÚDE: REFLEXÕES ACERCA DA JURISDIÇÃO CONSTITUCIONAL

absolutista. Surge assim, uma nova visão de Estado. Aqui, segundo leciona Böckenförde, o Estado de direito tem por fundamento o indivíduo, ele não é uma criação de Deus, mas sim uma comunidade (res pública) a serviço do interesse comum de todos os indivíduos ${ }^{17}$.

Nesse novo contexto, a burguesia em ascensão exige a limitação do poder, a igualdade formal, a proteção dos direitos e segurança jurídica. Nesta senda, os direitos do indivíduo se apresentam como um limite à atuação do Estado.

Destaca Böckenförde que o fundamento do Estado de Direito reside agora em ser a garantia da liberdade e da propriedade dos cidadãos, cuja finalidade é promover o interesse comum dos indivíduos. $\mathrm{E}$ isto é o que constitui precisamente seu caráter de comunidade ${ }^{18}$.

Desse modo, a burguesia que já detinha o poder econômico passa a exigir acima de tudo a efetividade dos princípios da liberdade e da propriedade, necessita para tanto, de um Estado não interventor, cujos poderes sejam limitados. Surge, assim, a necessidade de se estabelecer instrumentos para a limitação do poder. Nesta lógica, o princípio da legalidade e a separação dos poderes ganham respaldo.

O princípio da legalidade surge como uma vinculação do Estado à lei. Böckenförde aduz que, a lei criada deste modo obriga juridicamente a prática de uma ação por parte da administração, por ela vinculada e limitada. Logo, a administração apenas pode agir nos limites do expressamente disciplinado em lei ${ }^{19}$.

No mesmo ímpeto, a separação dos poderes buscava dividir as funções do Estado e com isso fracionar o poder. Acerca do tema Böckenförde entende que:

La $<<$ divisón de poderes >> se defiende y se acepta solo por lo que se refiere a laorganización autónoma del poder legislativo. Pero, considerada em si misma, esta idea se rechaza como uma amenaza para La unidaddel poder del Estadotantrabajosamente lograda-, pues, tomando pie em Montesquieu, el principio de ladivisión de poderes se entiende más em el sentido de uma distribuición de competências estatales entre las diferentes fuerzas político- sociales que em el de una mera articulación de funciones ${ }^{20}$.

Todos estes fatores vão conduzir ao fortalecimento do constitucionalismo, vez que ganha fôlego a ideia de contrato social, para tanto é preciso que o poder não seja mais transferido de

\footnotetext{
${ }^{17}$ BÖCKENFÖRDE, Ernst-Wolfgang. Estudios sobre el Estado de Derecho y La Democracia. Madrid: Trotta, 2000 , p. 19.

${ }^{18}$ Ibid., p. 21-22.

${ }^{19}$ Ibid., p. 23

${ }^{20}$ BÖCKENFÖRDE, Ernst-Wolfgang. Estudios sobre el Estado de Derecho y La Democracia. Madrid: Trotta, 2000, p. 20.
} 
A JUDICIALIZAÇÃO DA POLÍTICA E O PROTAGONISMO DOS JUÍZES NAS DECISÕES QUE ENVOLVEM O DIREITO CONSTITUCIONAL À SAÚDE: REFLEXÕES ACERCA DA JURISDIÇÃO CONSTITUCIONAL

um "ser superior" para o soberano, ele necessita ser "certo e limitado". Logo, a Constituição passa a ser o documento legal responsável por regular as funções e os limites do Estado.

Sob esta perspectiva, a Revolução Francesa de 1789 pode ser considerada como a fonte deste novo constitucionalismo, uma vez que, com a queda dos modelos econômico e político, surge um novo paradigma que, partindo do pressuposto de que o indivíduo está no centro da teoria política, coloca o Estado como sendo criado por um pacto firmado entre homens livres e iguais que a ele delegam a função de assegurar as suas liberdades e os seus direitos ${ }^{21}$.

Assim, passa a vigorar o entendimento de que o Estado não está a serviço do divino ou de uma vontade superior e sim a serviço dos homens e, sendo assim, passa a ser cabível a limitação do poder e a sua tripartição.

Todo este processo se dá, por sua vez, tendo como pano de fundo a instauração do Estado liberal, movido e gerido pelos interesses da burguesia, segundo os princípios iluministas do racionalismo e do antropocentrismo. Ao partir do pressuposto de que o homem é anterior ao Estado, isto é, a partir da compreensão de que ele é o seu fundamento, dá-se uma inversão na perspectiva da garantia dos direitos dos cidadãos e dos deveres do Estado, que passa a ser regido por dois princípios fundamentais: o princípio da distribuição e o princípio da organização 22 .

Dentro deste contexto, o princípio da legalidade surge para fundamentar uma intervenção mínima do Estado. Logo, as intervenções do ente público passam a ser admitidas somente em sede de exceção, ou seja, unicamente quando esta intervenção se der com fulcro na lei. Assim, não havendo previsão legal, o órgão estatal encontra-se impedido de agir. $\mathrm{Na}$ contramão aos particulares somente é vedado o que a lei expressamente proibir.

Da análise do princípio supra se compreende a essência do pensamento liberal que busca um estado regulado preponderantemente pelas relações estabelecidas entre particulares, em um espaço politicamente neutro e que apresenta como regulador unicamente a figura do mercado.

Para que fosse possível uma verdadeira limitação do poder, adotou-se um sistema de separação de poderes, independentes e harmônicos entre si, de modo que os mesmos não ficassem concentrados na mão de uma única pessoa.

${ }^{21}$ LEAL, Mônia Clarissa Henning. Jurisdição Constitucional aberta: reflexões sobre a legitimidade e os limites da jurisdição constitucional na ordem democrática. Uma abordagem a partir das teorias constitucionais alemã e norte-americana. Rio de Janeiro: Lumen Juris, 2007, p. 08.

22 Ibid., p. 08. 
A JUDICIALIZAÇÃO DA POLÍTICA E O PROTAGONISMO DOS JUÍZES NAS DECISÕES QUE ENVOLVEM O DIREITO CONSTITUCIONAL À SAÚDE: REFLEXÕES ACERCA DA JURISDIÇÃO CONSTITUCIONAL

Nesta perspectiva, o Estado passa a ter competência e atribuições bem delimitadas, sendo que o melhor instrumento para ordenar estes regramentos sobre competências e atribuições- e para assegurar os direitos individuais de uma maneira neutra e racional- é a lei, que pode ser caracterizada como uma regra geral (norma geral) que surge com o consentimento do povo- por meio do sistema representativo- num procedimento caracterizado pela discussão e pela publicidade ${ }^{23}$.

Toda essa mudança de modelo acarreta também uma compreensão diferenciada com relação ao conceito de justiça, a sensação que se tem é que neste período se abandona a concepção filosófica para se vivenciar uma concepção legalista.

Neste contexto, pode-se afirmar que, em tal período, o direito abandona a sua preocupação com o justo e com o injusto, e passa a se concentrar no aspecto procedimental, ou seja, na obediência a procedimentos e na correta utilização dos instrumentos instituídos pela própria lei. Destarte, a questão central de que se ocupa não é mais considerar se determinada conduta é boa ou má, certa ou errada, mas sim em estabelecer autorizações e permissões ${ }^{24}$.

Neste período, em face do fascínio e da preponderância que a lei exercia frente aos demais elementos, visualiza-se uma certa proeminência do Poder Legislativo frente aos demais.

Embora o Estado Liberal, tenha representado um avanço em face do modelo anteriormente vigente, ele não ficou imune a criticas. A crítica socialista atacou esse conceito formal de Estado de Direito, uma vez que o mesmo havia consolidado a posição econômica da burguesia, entendendo que o Estado de Direito deveria atender as exigências da democracia social do proletariado, conduzindo o Estado a uma organização baseada na igualdade material, econômica e social ${ }^{25}$.

As inúmeras críticas, associadas a revolta e reivindicações da massa de trabalhadores, conduziu ao inevitável surgimento do Estado de Bem Estar Social, onde algumas garantias de cunho social passam a ser implementadas. Nesse modelo, há uma renúncia ao conceito da lei como norma geral para o âmbito da administração prestacional, admitindo-se as chamadas “leis medida”, de natureza jurídica especial, responsáveis por dirigir e regular diretamente situações concretas. Estas leis passam a ser um instrumento necessário para um legislador que intervêm na

\footnotetext{
${ }^{23}$ LEAL, Mônia Clarissa Henning. Jurisdição Constitucional aberta: reflexões sobre a legitimidade e os limites da jurisdição constitucional na ordem democrática. Uma abordagem a partir das teorias constitucionais alemã e norte-americana. Rio de Janeiro: Lumen Juris, 2007, p. 10.

${ }^{24}$ Ibid., p. 13.

${ }^{25}$ BÖCKENFÖRDE, Ernst-Wolfgang. Estudios sobre el Estado de Derecho y La Democracia. Madrid: Trotta, 2000, p. 23.
} 
A JUDICIALIZAÇÃO DA POLÍTICA E O PROTAGONISMO DOS JUÍZES NAS DECISÕES QUE ENVOLVEM O DIREITO CONSTITUCIONAL À SAÚDE: REFLEXÕES ACERCA DA JURISDIÇÃO CONSTITUCIONAL

economia e na sociedade configurando, dirigindo e promovendo objetivos próprios do Estado social $^{26}$.

Posteriormente, tem-se a passagem para um conceito material de Estado de Direito onde há a renúncia ao positivismo jurídico, aqui a Constituição não fica restrita a disciplinar os limites do poder do Estado, passando a positivar os valores fundamentais da ordem da vida em comum ${ }^{27}$. Com isso ganha espaço a democracia como princípio constitucional, a partir do qual o poder do Estado precisa se articular de tal forma que tanto sua organização quanto o seu exercício derivem sempre da vontade do povo e possa a ele ser atribuído ${ }^{28}$. Logo, a democracia se refere a formação, legitimação e controle dos órgãos que exercem o poder. Já o Estado de Direito, tem na limitação e vinculação do poder do Estado, o fim de garantir a liberdade individual e social. Da conexão de ambos os princípios surge o Estado Democrático de Direito previsto na Lei Fundamental ${ }^{29}$.

Na sociedade contemporânea, cujo modelo vigente é o do Estado Democrático de Direito, o que se observa é uma ampla ascensão do Poder Judiciário e, de certo modo, a sua supremacia frente aos demais. Acerca do assunto, Maus refere que "não se trata simplesmente do crescimento na ampliação objetiva das funções do Judiciário. Essa evolução é acompanhada por uma representação da Justiça por parte da população, que ganha contornos de veneração religiosa" 30 .

O fator que atribui tamanha força ao Poder Judiciário, sobretudo aos Tribunais Constitucionais, é a positivação dos princípios fundamentais no texto da Constituição Federal. Tais princípios fazem com que todas as questões relevantes no que tange a vida de um indivíduo em um Estado perpassem pelo prisma da Constituição, gerando assim, a competência de análise do caso concreto por parte dos referidos Tribunais.

Alexy destaca com propriedade que:

A força rompante da interpretação constitucional resulta dos três extremos primeiro citados, do escalão hierárquico supremo, da força de concretização suprema e do conteúdo sumamente importante. Quem tiver êxito, o tribunal

\footnotetext{
${ }^{26}$ Ibid., p. 38-39,

${ }^{27}$ Ibid., p. 40.

${ }^{28}$ Ibid., p. 47.

${ }^{29}$ Ibid., p. 119.

${ }^{30}$ MAUS, Ingeborg. O Judiciário como superego da sociedade- sobre o papel da atividade jurisprudencial na "sociedade órfão”. Tradução de MartonioMont' Alverne Barreto Lima e Paulo Menezes de Albuquerque. In: Novos Estudos, n. 58. São Paulo: CEBRAP, novembro de 2000, p. 126.
} 
A JUDICIALIZAÇÃO DA POLÍTICA E O PROTAGONISMO DOS JUÍZES NAS DECISÕES QUE ENVOLVEM O DIREITO CONSTITUCIONAL À SAÚDE: REFLEXÕES ACERCA DA JURISDIÇÃO CONSTITUCIONAL

decide, ao fim e ao cabo, sobre a constitucionalidade e com isso- independente de sua designação- desempenha a tarefa de um tribunal constitucional, de convencer de sua concepção sobre a interpretação dos direitos fundamentais alcançou o que no processo político ordinário é inalcançável: ele tornou sua concepção sobre coisas sociais e políticas sumamente importantes praticamente partes integrantes da constituição e, com isso, tomou da ordem do dia política ${ }^{31}$.

Assim, frente a questões como a crise de representação, de circunstâncias como a necessidade de concretização dos direitos fundamentais e da ideia consolidada de existência de um núcleo essencial de direitos, cuja limitação pode ocorrer somente até o ponto em que não atinja o núcleo essencial dos direitos fundamentais, ou seja, um direito fundamental apenas pode ser restringido em face de outro direito fundamental, o Poder Judiciário passa a exercer um protagonismo nunca antes visto.

A questão da jurisdição constitucional e sua legitimidade tem sido objeto de inúmeros e acirrados debates teóricos ao longo do tempo, especialmente desde meados do século passado, quando, em meio ao segundo pós-guerra e ao florescimento de um Estado vinculado à noção de direitos humanos, deu-se um recrudescimento das funções e das atividades dos chamados Tribunais Constitucionais, que, apesar de suas variantes, passaram a avocar para si um papel importante no sentido de concretização e de preservação da ordem social estabelecida ${ }^{32}$.

As criticas da doutrina, direcionadas à Jurisdição constitucional e ao protagonismo dos juízes, diante de sua atuação de forma a judicializar a política, são muitas que vão desde a compreensão de que a jurisdição é paternalista até a de que o Tribunal se legitima a si mesmo, a partir da autoreferência. A despeito das referidas críticas, o que vem se observando é um protagonismo cada vez maior do Poder Judiciário no Brasil.

\footnotetext{
${ }^{31}$ ALEXY, Robert. Direitos Fundamentais no Estado Constitucional democrático: para a relação entre direitos do homem, direitos fundamentais, democracia e jurisdição constitucional. Tradução de Luís Afonso Heck. In: Revista de Direito Administrativo, n. 217, Rio de Janeiro, jul./set. 1999,p. 64.

${ }^{32}$ LEAL, Mônia Clarissa Henning. Jurisdição Constitucional aberta: reflexões sobre a legitimidade e os limites da jurisdição constitucional na ordem democrática. Uma abordagem a partir das teorias constitucionais alemã e norte-americana. Rio de Janeiro: Lumen Juris, 2007, p. 06.
} 


\section{A JUDICIALIZAÇÃO DA POLÍTICA: UMA ANÁLISE DOS REFLEXOS DO ATIVISMO DIGITAL NO DIREITO À SAUDE}

A proeminência do Poder Judiciário conduziu para que o fenômeno do ativismo judicial ganhasse corpo. Referido fenômeno encontra-se ancorado na discussão acerca da efetivação dos direitos fundamentais, sobretudo, dos direitos fundamentais sociais, que diante da ineficácia das políticas públicas ou de seu alcance restrito, fazem com que essas demandas cheguem até o Judiciário, assumindo este o papel de agente concretizador dos direitos sociais.

As fortes violações aos direitos humanos, praticadas por ocasião da II Guerra Mundial, acabaram por gerar um forte movimento no sentido de resgate e de fortalecimento da noção desses direitos, que passaram a ocupar um lugar de destaque nas Constituições. Neste cenário, os maiores avanços ocorreram nos países mais afetados pelos conflitos e pelos regimes totalitários que desenvolvem também as jurisdições constitucionais mais atuantes e densas do cenário europeu ${ }^{33}$.

Hodiernamente, no Brasil, dentre os direitos sociais mais pleiteados em Juízo e que demonstram uma ampla intervenção do Judiciário, destaca-se o direito à saúde. Tamanha proteção justifica-se no fato de que as pessoas que necessitam da efetivação deste direito, em regra, encontram-se em situação de vulnerabilidade social, assistencial e psicológica, em vista da própria debilidade e restrições no exercício das atividades, até então normalmente praticadas, provocadas pela doença.

Ademais, a efetivação do direito à saúde possui ampla correspondência com a efetivação do direito humano e fundamental à vida, o que por si só fundamenta a prioridade e atenção no julgamento destas questões por parte dos tribunais constitucionais. A proteção do direito à vida e, por conseguinte, a perspectiva de uma vida digna para todos os cidadãos representam ferramentas de primordial importância na concretização dos direitos humanos.

A justificativa comumente utilizada para fundamentar as sentenças, cujo pedido consiste em acesso a medicamentos ou a tratamentos médicos, é a de que diante da omissão por parte

\footnotetext{
${ }^{33}$ LEAL, Mônia Clarissa Henning. Jurisdição Constitucional aberta: reflexões sobre a legitimidade e os limites da jurisdição constitucional na ordem democrática. Uma abordagem a partir das teorias constitucionais alemã e norteamericana. Rio de Janeiro: Lumen Juris, 2007, p. 51-52.
} 
A JUDICIALIZAÇ̃̃O DA POLÍTICA E O PROTAGONISMO DOS JUIZZES NAS DECISÕES QUE ENVOLVEM O DIREITO CONSTITUCIONAL À SAÚDE: REFLEXÕES ACERCA DA JURISDIÇÃO CONSTITUCIONAL

dos demais poderes, não pode o Poder Judiciário se esquivar da tarefa de garantir a efetivação do direito à vida.

Em todos os graus de jurisdição, visualizam-se inúmeros julgados neste sentido. Nesta senda colaciona-se trecho da sentença de $1^{\circ} \mathrm{Grau}$, da lavra da Juíza de Direito $\mathrm{Dr}^{\mathrm{a}}$. Lisiane Marques Pires Sasso, da $3^{\circ}$ Vara Judicial da Comarca de Palmeira das Missões, Rio Grande do Sul:

O artigo 196 da Constituição Federal preconiza que a saúde é um direito de todos e dever do Estado, garantido mediante políticas sociais e econômicas que visem à redução do risco e de outros agravos e ao acesso universal e igualitário às ações e serviços para sua promoção, proteção e recuperação. Dessa forma, diante da impossibilidade do cidadão de prover por seus próprios meios a manutenção de sua saúde, constitui-se em obrigação solidária de todos os entes públicos.

$[\ldots]$

No artigo acima transcrito, o Constituinte de 1988 sinalizou claramente que tipo de saúde deve ser proporcionada aos cidadãos brasileiros. Em face da referida determinação constitucional compete aos nossos governantes a instituição de políticas sociais que visem alcançar à saúde curativa e preventiva, bem como promovam a qualidade de vida, preocupação que restou estampada na redação do artigo 225 da Constituição Federal.

Para uma melhor análise das questões nestes autos discutidas, cabe trazer à baila o conceito de saúde.

Segundo Germano Schwartz (in Direito à Saúde: efetivação em uma perspectiva sistêmica, Porto Alegre, Livraria do Advogado, 2001, p. 35), o marco teóricoreferencial do conceito de saúde foi erigido em 26 de julho de 1946. O preâmbulo da Constituição da Organização Mundial da Saúde (OMS), órgão da ONU, refere que a 'saúde é o completo bem-estar físico, mental e social e não apenas a ausência de doenças'. Tal conceito é o primeiro princípio básico para a felicidade, as relações harmoniosas e a segurança de todos os povos. Segue o referido autor asseverando que a OMS, em seu conceito, adentra na chamada 'promoção' da saúde ao propor que a saúde não é apenas a ausência de doenças, mas também um completo bem-estar, seja físico, mental ou social.

[...]

É bem verdade que a efetivação da saúde necessita da organização de políticas econômicas e sociais que visem à maximização do direito à saúde, as quais, como é do conhecimento de todos, vêm sendo realizadas de forma insatisfatória, em completa desobediência aos preceitos constitucionais. Percebe-se, com muita clareza, a falta de vontade política por parte dos Poderes Públicos, especialmente o Poder Executivo - por ser ele o controlador das verbas referentes à matéria - que relegam a saúde a segundo plano em detrimento de outras opções que julgam mais importantes.

Por tais motivos, os cidadãos menos favorecidos economicamente e que não têm condições de arcar com os custos sempre altos de qualquer tratamento médico têm no Poder Judiciário um resguardo para a busca de seu direito assegurado constitucionalmente.

Nessa seara, embora secundária a atuação do Poder Judiciário, é ele o único caminho que tem o cidadão para buscar a correção das desigualdades ocorridas no campo sanitário. 
A JUDICIALIZAÇ̃̃O DA POLÍTICA E O PROTAGONISMO DOS JUIZZES NAS DECISÕES QUE ENVOLVEM O DIREITO CONSTITUCIONAL À SAÚDE: REFLEXÕES ACERCA DA JURISDIÇÃO CONSTITUCIONAL

A mesma linha de raciocínio pode ser visualizada nos arrestos proferidos pelas diversas Câmaras Cíveis do Tribunal de Justiça gaúcho:

AGRAVO DE INSTRUMENTO. DIREITO PÚBLICO NÃO ESPECIFICADO. CONSTITUCIONAL. FORNECIMENTO DE REMÉDIOS A NECESSITADO. LEGITIMAÇÃO PASSIVA DO ESTADO. CACONS. O direito à saúde é assegurado a todos, devendo os necessitados receber do ente público os medicamentos necessários. Inteligência do artigo 196 da Constituição Federal. O Estado possui legitimidade passiva na demanda visando ao fornecimento de medicamentos a necessitado, obrigação não afastada ante a existência dos CACONs (Centro de Alta Complexidade em Oncologia). Precedentes do TJRGS, STJ e STF. Agravo de instrumento com seguimento negado. (Agravo de Instrumento $\mathrm{N}^{\circ} 70039976527$, Vigésima Segunda Câmara Cível, Tribunal de Justiça do RS, Relator: Carlos Eduardo Zietlow Duro, Julgado em 18/11/2010) (grifei)

AGRAVO DE INSTRUMENTO. DIREITO PÚBLICO NÃO ESPECIFICADO. DIREITO À SAÚDE. AÇÃOO ORDINÁRIA. INSUMO/ALIMENTO. MUNICÍPIO DE PASSO FUNDO. LEGITIMIDADE PASSIVA. AUSÊNCIA DE RECURSOS FINANCEIROS. BLOQUEIO DE VALORES. 1. A promoção da saúde constitui-se em dever do Estado, em todas as suas esferas de poder, caracterizando-se a solidariedade entre União, Estados e Municípios, do que decorre a legitimidade passiva do Município de Passo Fundo. Exegese dos artigos $5^{\circ}$, inciso XXXV, e 196, ambos da Constituição Federal. 2. Versando a controvérsia em termos de mínimo existencial da vida humana, é de se impor a adoção de medidas de eficácia objetiva para que esse interesse público indisponível seja resguardado, como no caso, em que está devidamente demonstrada a necessidade do alimentado postulado e a impossibilidade da parte autora em custeá-lo. 3 . Admissível, nos termos do artigo 461 , $\$ 5^{\circ}$, do CPC, a ordem de bloqueio de valores correspondente ao custo do insumo/alimento, não se caracterizando malferimento à regra inscrita no artigo 100, da Constituição Federal, em face do direito à vida, constitucionalmente assegurado. No caso, não houve a determinação do comando, mas mera advertência, não configurando, também por este motivo, o cabimento do recurso. NEGADO SEGUIMENTO AO RECURSO. (Agravo de Instrumento $\mathrm{N}^{\circ} 70039928411$, Terceira Câmara Cível, Tribunal de Justiça do RS, Relator: Rogerio Gesta Leal, Julgado em 18/11/2010) (grifei)

APELAÇÃO CÍVEL. ECA. FORNECIMENTO DE MEDICAMENTO. CERCEAMENTO DE DEFESA. PROVA PERICIAL. DESNECESSIDADE. LEGITIMIDADE PASSIVA. SOLIDARIEDADE ENTRE OS ENTES ESTATAIS. Caso concreto. Fornecimento dos medicamentos INSULINA LANTUS (GLARGINA), TIRAS ACCU-CHECK ACTIVE e INSULINA NOVORAPID (ASPART), enquanto perdurar a patologia. DIABETES MELLITU TIPO 1 (CID E 10), conforme laudo médico. Cerceamento de defesa e prova pericial. Não merece amparo a prefacial de nulidade, porquanto os laudos médicos constantes nos autos e subscritos por médica da Secretaria da Saúde do próprio Município, são suficientes para comprovar a necessidade do menor em receber o medicamento pleiteado. Legitimidade passiva e Solidariedade. Os entes estatais são solidariamente responsáveis pelo atendimento do direito fundamental ao direito à saúde, não havendo razão para cogitar em ilegitimidade passiva ou em obrigação exclusiva de um deles. Nem mesmo se o remédio, substância ou tratamento postulado não se encontre na respectiva lista, 
A JUDICIALIZAÇ̃̃O DA POLÍTICA E O PROTAGONISMO DOS JUÍZES NAS DECISÕES QUE ENVOLVEM O DIREITO CONSTITUCIONAL À SAÚDE: REFLEXÕES ACERCA DA JURISDIÇÃO CONSTITUCIONAL

ou se encontra na lista do outro ente. NEGARAM PROVIMENTO. (Apelação Cível № 70039645072, Oitava Câmara Cível, Tribunal de Justiça do RS, Relator: Rui Portanova, Julgado em 18/11/2010) (grifei)

APELACC̃̃O CIVEL. FORNECIMENTO DE MEDICAMENTOS. INTERESSE DE AGIR. ILEGITIMIDADE PASSIVA. NECESSIDADE E UTILIDADE DA TUTELA JURISDICIONAL. 1. Para aferir o interesse de agir não é necessário que a parte esgote, ou ainda, ingresse com o pedido na via administrativa. 2. O direito à saúde, superdireito de matriz constitucional, há de ser assegurado, com absoluta prioridade às crianças e adolescentes e é dever do Estado (União, Estados e Municípios) como corolário do direito à vida e do princípio da dignidade da pessoa humana. NEGARAM PROVIMENTO. UNÂNIME. (Apelação Cível № 70038803870, Oitava Câmara Cível, Tribunal de Justiça do RS, Relator: Luiz Felipe Brasil Santos, Julgado em 18/11/2010) (grifei)

0 posicionamento ativo na defesa do direito fundamental à vida e do direito social à saúde é pacífico também no Supremo Tribunal Federal:

DIREITO CONSTITUCIONAL. DIREITO A SAÚDE. AGRAVO REGIMENTAL EM AGRAVO DE INSTRUMENTO. IMPLEMENTAÇÃO DE POLÍTICAS PÚBLICAS. ACC̃̃O CIVIL PÚBLICA. PROSSEGUIMENTO DE JULGAMENTO. AUSÊNCIA DE INGERÊNCIA NO PODER DISCRICIONÁRIO DO PODER EXECUTIVO. ARTIGOS $2^{\circ}$, 6 $6^{\circ}$ E 196 DA CONSTITUIÇÃO FEDERAL. 1. O direito a saúde é prerrogativa constitucional indisponível, garantido mediante a implementação de políticas públicas, impondo ao Estado a obrigação de criar condições objetivas que possibilitem o efetivo acesso a tal serviço. 2. É possível ao Poder Judiciário determinar a implementação pelo Estado, quando inadimplente, de políticas públicas constitucionalmente previstas, sem que haja ingerência em questão que envolve o poder discricionário do Poder Executivo. Precedentes. 3. Agravo regimental improvido.

(Al 734487 AgR, Relator(a): Min. ELLEN GRACIE, Segunda Turma, julgado em 03/08/2010, DJe-154 DIVULG 19-08-2010 PUBLIC 20-08-2010 EMENT VOL-02411-06 PP-01220)

EMENTA: Suspensão de Liminar. Agravo Regimental. Saúde pública. Direitos fundamentais sociais. Art. 196 da Constituição. Audiência Pública. Sistema Único de Saúde - SUS. Políticas públicas. Judicialização do direito à saúde. Separação de poderes. Parâmetros para solução judicial dos casos concretos que envolvem direito à saúde. Responsabilidade solidária dos entes da Federação em matéria de saúde. Ordem de regularização dos serviços prestados em hospital público. Não comprovação de grave lesão à ordem, à economia, à saúde e à segurança pública. Possibilidade de ocorrência de dano inverso. Agravo regimental a que se nega provimento. (SL 47 AgR, Relator(a): Min. GILMAR MENDES (Presidente), Tribunal Pleno, julgado em 17/03/2010, DJe-076 DIVULG 29-04-2010 PUBLIC 30-04-2010 EMENT VOL-02399-01 PP-00001)

Diante do exposto, as criticas mais fervorosas da doutrina no que tange a crescente judicialização e ao ativismo judicial se dão em três aspectos preponderantes: quanto 
A JUDICIALIZAÇ̃̃O DA POLÍTICA E O PROTAGONISMO DOS JUIZZES NAS DECISÕES QUE ENVOLVEM O DIREITO CONSTITUCIONAL À SAÚDE: REFLEXÕES ACERCA DA JURISDIÇÃO CONSTITUCIONAL

ajudicialização da política, quanto a violação ao princípio da separação dos poderes e no que tange a falta de mecanismos de controle social ao Poder Judiciário.

Assim, com referência ao primeiro aspecto, leciona Cittadino que o processo de judicialização da política não precisa invocar o domínio dos tribunais, nem defender uma ação paternalista por parte do Poder Judiciário, uma vez que a própria Carta Magna institui mecanismos processuais para garantir a eficácia de seus princípios, de modo que a construção de uma cidadania juridicamente participativa depende muito mais do nível de mobilização política do que da atuação dos tribunais, embora essa não possa ser dispensada ${ }^{34}$.

Barroso, por sua vez, entende que a expansão do Judiciário não deve desviar a atenção da real disfunção que aflige a democracia brasileira: a crise de representatividade, legitimidade e funcionalidade do Poder Legislativo. Logo, o que a democracia brasileira necessita é de reforma política ${ }^{35}$.

Alexy destaca que se pode falar em uma luta pela interpretação dos direitos fundamentais, uma vez que eles interessam a todos. No entanto, o árbitro nessa luta não é o verdadeiro destinatário desses direitos, qual seja: o povo e sim o Tribunal Constitucional $^{36}$.

Ainda Böckenförde aduz, que o "Direito Constitucional, antes entendido como uma força configuradora tanto da organização como das instituições, se transforma em um processo político que se move por si mesmo. Ficando nas mãos do intérprete". E ao final aponta o seguinte questionamento: Isto é correto ${ }^{37}$

No que tange ao segundo aspecto, alguns autores vinculam o ativismo judicial a uma ofensa ao princípio da separação dos poderes. Neste sentido Cittadino refere que, o protagonismo recente dos Tribunais Constitucionais e Cortes Supremas além de transformar em questão problemática os princípios da separação dos poderes e da neutralidade política do Poder Judiciário, inaugura um tipo inédito de espaço público, desvinculado das clássicas instituições

${ }^{34}$ CITTADINO, Gisele. Judicialização da política, constitucionalismo democrático e separação dos poderes. In: VIANNA, Luiz Werneck (org.). A democracia e os três poderes no Brasil. Belo Horizonte: Editora UFMG; Rio de Janeiro: IUPERJ/FAPERJ, 2002, p. 39.

${ }^{35}$ BARROSO, Luís Roberto. Judicialização, ativismo e legitimidade democrática. In: Revista Eletrônica de Direito do Estado, n. 18, abr./jun. 2009, p. 14.

${ }^{36}$ ALEXY, Robert. Direitos Fundamentais no Estado Constitucional democrático: para a relação entre direitos do homem, direitos fundamentais, democracia e jurisdição constitucional. Tradução de Luís Afonso Heck. In: Revista de Direito Administrativo, n. 217, Rio de Janeiro, jul./set. 1999, p. 64.

${ }^{37}$ BÖCKENFÖRDE, Ernst-Wolfgang. Estudios sobre el Estado de Derecho y La Democracia. Madrid: Trotta, 2000, p. 196. 
A JUDICIALIZAÇÃO DA POLÍTICA E O PROTAGONISMO DOS JUÍZES NAS DECISÕES QUE ENVOLVEM O DIREITO CONSTITUCIONAL À SAÚDE: REFLEXÕES ACERCA DA JURISDIÇÃO CONSTITUCIONAL

político-representativas ${ }^{38}$. Seguindo na mesma linha de raciocínio, Maus aduz que, "a Justiça transforma em fetiche sua independência através de exigências políticas corporativas, ao mesmo tempo em que, ao negar fundamentalmente sua vinculação à legalidade, exige sua independência do recém-democratizado Poder Legislativo" 39 .

Por fim, no que se refere ao terceiro aspecto, a critica concentra-se na falta de mecanismos de controle social da atuação do Poder Judiciário. Assim, Maus afirma que:

Quando a Justiça ascende ela própria à condição de mais alta instância moral da sociedade passa a escapar de qualquer mecanismo de controle social; controle ao qual normalmente se deve subordinar toda instituição do Estado em uma forma de organização política democrática. No domínio da Justiça que contrapõe um direito "superior", dotado de atributos morais, ao simples direito dos outros poderes do Estado e à sociedade é notória a regressão a valores pré-democráticos de parâmetros de integração social ${ }^{40}$.

Diante do exposto, observa-se que a figura do ativismo judicial é ponto de grande polêmica, sobretudo, entre doutrinadores e magistrados, entretanto, não se pode olvidar que essa intervenção vem promovendo, em muitos campos, a efetividade e concretização de direitos fundamentais que não vinham sendo observados pelos demais poderes, de forma especial, no que tange ao campo de atuação do Poder Executivo, responsável pela efetivação dos mesmos no âmbito da vida de cada indivíduo. Frente a este aspecto se compreende que em muitos casos o ativismo é melhor do que a omissão.

Importante ressaltar que se o ativismo partir apenas do sistema ele se converte em disfunção judicial. Logo, o ideal seria que todos os setores da sociedade estivessem comprometidos com a defesa dos direitos fundamentais, não sendo passível de haver um único protagonista. Embora o ativismo seja uma garantia a mais na efetivação dos direitos fundamentais, não pode ser a única.

Em um país como o Brasil, onde as necessidades ainda são muitas, não resta dúvida de que a atuação do Poder Judiciário, no campo da promoção e garantia dos direitos fundamentais, é de grande relevância. Outrossim, é fundamental que o protagonismo do Poder Judiciário não ataque

\footnotetext{
${ }^{38}$ CITTADINO, Op. Cit., p. 17.

${ }^{39}$ MAUS, Ingeborg. O Judiciário como superego da sociedade: sobre o papel da atividade jurisprudencial na "sociedade órfão". Tradução de MartonioMont' Alverne Barreto Lima e Paulo Menezes de Albuquerque. In: Novos Estudos, n. 58. São Paulo: CEBRAP, novembro de 2000, p. 142-143

40 lbid., p. 129.
} 
A JUDICIALIZAÇÃO DA POLÍTICA E O PROTAGONISMO DOS JUÍZES NAS DECISÕES QUE ENVOLVEM O DIREITO CONSTITUCIONAL À SAÚDE: REFLEXÕES ACERCA DA JURISDIÇÃO CONSTITUCIONAL

as bases do Constitucionalismo Democrático, assim, torna-se indispensável a observância ao princípio da proporcionalidade a cada decisão proferida.

\section{CONCLUSÃO}

Através do presente trabalho, procurou-se fornecer um conhecimento inicial sobre a problemática que envolve a jurisdição constitucional, e aporta no sentido de ampliar o debate sobre a necessária efetivação dos direitos fundamentais e a democratização dos poderes estatais.

Com efeito, observou-se que as contribuições da obra de Peter Häberle são de suma importância para a compreensão do contexto em que habita o constitucionalismo contemporâneo, uma vez que o referido autor trabalha com a ideia da Constituição enquanto reflexo de um fenômeno cultural, que traz consigo muito dos valores do Estado e do povo a que é endereçada.

O presente artigo sustentou-se no argumento de que frente ao protagonismo do Poder Judiciário e ao crescente ativismo praticado pelos tribunais constitucionais é preciso que todos os setores da sociedade reconheçam o seu dever de estarem comprometidos com a defesa dos direitos fundamentais, não sendo passível de haver um único protagonista. Nesta senda, reconhece-se o ativismo como uma garantia na efetivação dos direitos fundamentais, entretanto, não pode ser a única.

Por fim, diante da compreensão de que em um país como o Brasil onde as violações aos direitos fundamentais são muitas, enquanto não sejam criados outros meios de garantia e políticas públicas para a efetivação deste direito, a atuação do judiciário continuará a ser o único meio encontrado por inúmeros cidadãos, a fim de terem seus direitos fundamentais assegurados. Logo, urge que tamanho protagonismo preserve as bases do Constitucionalismo Democrático e se utilize do princípio da proporcionalidade a cada decisão proferida.

\section{REFERÊNCIAS}

ALEXY, Robert. Tradução de Luís Afonso Heck. In: Revista de Direito Administrativo. Direitos Fundamentais no Estado Constitucional democrático: para a relação entre direitos do 
A JUDICIALIZAÇ̃̃O DA POLÍTICA E O PROTAGONISMO DOS JUIZZES NAS DECISÕES QUE ENVOLVEM O DIREITO CONSTITUCIONAL À SAÚDE: REFLEXÕES ACERCA DA JURISDIÇÃO CONSTITUCIONAL

homem, direitos fundamentais, democracia e jurisdição constitucional. Rio de Janeiro, 1999. n. 217, pg 55-66.

BARROSO, Luís Roberto. In: Revista Eletrônica de Direito do Estado. 2009, n. 18.

BÖCKENFÖRDE, Ernst-Wolfgang. Estudios sobre el Estado de Derecho y La Democracia. Madrid: Trotta, 2000.

BRASIL. Tribunal de Justiça do Estado do Rio Grande do Sul. Agravo de instrumento com seguimento negado em relação a fornecimento de remédios de necessitado por parte do estado. Agravo de instrumento $N^{\circ} 70039976527$. Noeli Maria Knieling de Moraes e Estado do Rio Grande do Sul. Relator: Carlos Eduardo Zietlow Duro. Disponível em:

<http://www1.tjrs.jus.br/site_php/consulta/consulta_processo.php?nome_comarca=Tribunal+d e+Justi\%E7a\&versao=\&versao_fonetica $=1 \&$ tipo=1\&id_comarca=700\&num_processo_mask=700399 76527\&num_processo=70039976527\&codEmenta=3869239\&temIntTeor=true>. Acesso em: 28 nov. 2010.

BRASIL. Tribunal de Justiça do Estado do Rio Grande do Sul. Agravo de instrumento com seguimento de recurso negado em relação a fornecimento de remédios de necessitado por parte da prefeitura de Passo Fundo. Agravo de instrumento $N^{\circ} 70039928411$. Relator: Rogério Gesta Leal. Disponível em:

<http://www1.tjrs.jus.br/site_php/consulta/consulta_processo.php?nome_comarca=Tribunal+d e+Justi\%E7a\&versao=\&versao_fonetica=1\&tipo=1\&id_comarca=700\&num_processo_mask=700399 28411 \&num_processo=70039928411\&codEmenta $=3868411$ \&temIntTeor=true $>$. Acesso em: 28 nov. 2010.

BRASIL. Tribunal de Justiça do Estado do Rio Grande do Sul. Apelação cível com provimento negado em relação ao fornecimento de medicamentos com legitimidade passiva estatal. Apelação Cível $N^{\circ}$ 70039645072. Relator: Rui Portanova. Disponível em: <http://www1.tjrs.jus.br/site_php/consulta/consulta_processo.php?nome_comarca=Tribunal+d e+Justi\%E7a\&versao=\&versao_fonetica $=1 \&$ tipo=1\&id_comarca=700\&num_processo_mask=700396 45072\&num_processo=70039645072\&codEmenta=3869961\&temIntTeor=true>. Acesso em: 28 nov. 2010.

BRASIL. Tribunal de Justiça do Estado do Rio Grande do Sul. Apelação cível com provimento negado unânime, em relação ao fornecimento de medicamentos com ilegitimidade passiva. Apelação Cível № 70038803870. Relator: Luiz Felipe Brasil Santos. Disponível em:

$<$ http://www1.tjrs.jus.br/site_php/consulta/consulta_processo.php?nome_comarca=Tribunal+d e+Justi\%E7a\&versao=\&versao_fonetica $=1 \&$ tipo $=1 \& i d \_c o m a r c a=700 \&$ num_processo_mask=700388 03870\&num_processo=70038803870\&codEmenta=3870230\&temlntTeor=true>. Acesso em: 28 nov. 2010.

BRASIL. Tribunal de Justiça do Estado do Rio Grande do Sul. Sentença Cível Processo No 020/1.09.0004540-8. Juíza Prolatora: Lisiane Marques Pires Sasso. Disponível em: <http://www1.tjrs.jus.br/busca/?tb=proc>. Acesso em: 28 nov. 2010.

BRASIL. Supremo Tribunal Federal. Agravo regimental improvido em relação a políticas públicas do direito à saúde. Agravo regimental Al 734487. Relatora: Min. Ellen Gracie. 
A JUDICIALIZAÇÃO DA POLÍTICA E O PROTAGONISMO DOS JUIZZES NAS DECISÕES QUE ENVOLVEM O DIREITO CONSTITUCIONAL À SAÚDE: REFLEXÕES ACERCA DA JURISDIÇÃO CONSTITUCIONAL

Disponível em:

<http://www.stf.jus.br/portal/jurisprudencia/listarJurisprudencia.asp?s1=\%28734487\%2ENUME\% 2E+OU+734487\%2EACMS\%2E\%29\&base=baseAcordaos\&url=http: / / tinyurl.com/lffdroj>. Acesso em: 28 nov. 2010.

BRASIL. Supremo Tribunal Federal. Agravo regimental com provimento negado unânime em relação ao direito de saúde e a regulamentação dos serviços de saúde prestados por hospitais públicos. Agravo regimental SL 47. Relator: Min. Gilmar Mendes. Disponível em:

<http://www.stf.jus.br/portal/jurisprudencia/listarJurisprudencia.asp?s1=\%2847\%2ENUME\%2E+O U+47\%2EACMS\%2E\%29+\%28\%28GILMAR+MENDES\%29\%2ENORL\%2E+OU+\%28GILMAR+MENDES\%29\%2EN ORV\%2E+OU+\%28GILMAR+MENDES\%29\%2ENORA\%2E+OU+\%28GILMAR+MENDES\%29\%2EACMS\%2E\%29\& base=baseAcordaos\&url=http: / / tinyurl.com/m2v3ug2asp? >. Acesso em: 28 nov. 2010.

CITTADINO, Gisele. Judicialização da política, constitucionalismo democrático e separação dos poderes. In: VIANNA, Luiz Werneck (org.). A democracia e os três poderes no Brasil. Belo Horizonte: Editora UFMG; Rio de Janeiro: IUPERJ/FAPERJ, 2002.

HÄBERLE. Peter. Constituição e cultura: 0 direito ao feriado como elemento de identidade cultural do Estado Constitucional. Rio de Janeiro: Lumen Juris, 2008.

HÄBERLE, Peter. Hermenêutica Constitucional: a sociedade aberta dos intérpretes da Constituição- contribuição para a interpretação pluralista e procedimental da Constituição. Tradução de Gilmar Ferreira Mendes. Porto Alegre: Fabris, 1997.

HÄBERLE, Peter. Libertad, igualdad, fraternidad: 1789 como historia, actualidad y futuro del Estado Constitucional. Madrid: MinimaTrotta, 1998.

HÄBERLE, Peter. Os problemas da verdade no Estado Constitucional. Tradução de Urbano Carvelli. Porto Alegre: Fabris, 2008.

HÄBERLE, Peter. Teoria de laConstitución como ciencia de la cultura.Tradução de Emilio Mikunda. Madrid: Tecnos, 2002.

LEAL, Mônia Clarissa Henning. Jurisdição Constitucional aberta: reflexões sobre a legitimidade e os limites da jurisdição constitucional na ordem democrática. Uma abordagem a partir das teorias constitucionaisalemã e norte-americana. Rio de Janeiro: Lumen Juris, 2007.

MAUS, Ingeborg. Tradução de MartonioMont' Alverne Barreto Lima e Paulo Menezes de Albuquerque. In: Novos Estudos. O Judiciário como superego da sociedade- sobre o papel da atividade jurisprudencial na "sociedade órfão". São Paulo: CEBRAP, 2000. n. 58.

Recebido em: 07/05/2014 / Revisões em 14/10/2014 Aprovado em: 10/11/2014 